about how current workplace strategies to prevent the spread of COVID-19 may be having unintentional consequences on worker health and safety.

\section{P-440 CHRONIC EXPOSURE TO PESTICIDES (AGROTOXICS) BY ENDEMIC WORKERS IN THE STATE AND MUNICIPALITY OF RIO DE JANEIRO, BRAZIL.}

${ }^{1}$ Gabriel Silveira, Ana Silva, Priscila Vidal, Victor Figueiredo, Marcus Santos, Luiza Dantas, Marcos-Rogério Silva, Ébio-Willis Moreira, Roberto-Paulo Nunes, Socorro Setúbal, AntônioCarlos Cardoso, Monica Martins, Fátima Moreira, Leandro Carvalho, Luciana Gomes, MariaBlandina Santos, Luiz-Claúdio Meirelles, Isabele Costa-Amaral, Eline Gonçalves, Lia Augusto, Aline Gurgel, Márcia Mello, Liliane Teixeira, Ana Cristina Rosa, Karen Friedrich, Ariane Larentis. ${ }^{~}$ Sergio Arouca National School of Public Health (Ensp)

\subsection{6/OEM-2021-EPI.329}

Introduction The use of pesticides (agrotoxics), including some that were restrict or banned wordwide, is a key element of the Brazilian vector control strategy, making them potential exposure sources. This exposure is more intense for professionals directly involved with the manipulation and application of these substances, like the Endemic Workers (EW), who suffered for decades a process of continuous exposure to agrotoxics associated with several health problems, including neurotoxic damage and cancer.

Objectives Identify and characterize the harmfulness of agrotoxics used by endemic workers.

Methods Through a documentary research using official documents from the health departments of the state and municipality of Rio de Janeiro and a literature review, the agrotoxics used by the EW in the region between the years 2000 and 2019 and its implications to human health, were identify and analysed, aiming to contribute to the elaboration of the exposure profile of these workers.

Results The study identified a total of 11 active ingredients of pesticides in the products used in the state and municipality of Rio de Janeiro. Among the effects on humans associated with exposure to these substances, the neurotoxic effect of 7 of them (alpha-cypermethrin, bendiocarb, deltamethrin, phenitrothione, malathion, permethrin and temephos) and the carcinogenic potential of alpha-cypermethrin, malathion and permethrin stands out. During the pandemic, new agrotoxics have been introduced in vector control actions, containing clothianidin, deltamethrin, pralethrin, imidacloprid and Saccharopolyspora spinosa, agrotoxics that already have been associated with several health effects, so is likely that the EW will continue to be chronic exposed to harmful substances in their labour activities.

Conclusion The implications of the exposure to agrotoxics reinforce the need to reformulate the national vector control policy that employs them in a massive volume, exposing the EW category, as well as the general population and the environment to these harmful effects.

\section{P-442 ALLERGIC ASTHMA IN THE WORKPLACE}

Jihen Hsinet, Nihel Khouja, Saloua Ismail, 'Amani Dallagi, Siwar Chemingui, Ines Aissa, Aida Benzarti, Abdelmajid Ben Jemaa. ${ }^{1}$ Faculté de médecine de Tunis, Tunisia

\subsection{6/OEM-2021-EPI.330}

Introduction Allergic asthma is currently the most frequent respiratory pathology in the workplace. Whether induced or aggravated by the work environment, the adequacy between this morbid state and work is often subject to reevaluation.

Objectives Study the socio-professional, clinical, para-clinical characteristics of allergic asthma in the workplace, to assess their impact on the ability to work and to compare occupational asthma (OA) and work exacerbated a sthma (WEA) in terms of associated professional and extra-professional factors and in terms of repercussions on aptitude.

Methods retrospective study of occupational allergic asthma collected from the Department of Occupational Medicine of La Rabta hospital during the period from January 2000 to December 2020.

Results This is a series of 232 cases of work-related allergic asthma, including $76.7 \% \mathrm{OA}$ and $23.3 \%$ WEA. The mean age was $40.28 \pm 8.96$ years. The female gender was represented in $50.9 \%$ of cases. The sectors that provided the most asthma were textile sector (10\%) and health sector (10.9\%). The clinical symptoms were dominated by wheezing dyspnea (51.5\%). The responsible agents were high molecular weight allergens (HMW) in particular vegetable textile dust $(9.9 \%)$, low molecular weight (LMW) such as isocyanate $(11.6 \%)$, formaldehyde $(11.2 \%)$. The age and seniority were higher in the OA group, $(p=0.002)$ and $(p$ $=0.005)$. This group was associated with the grade of unskilled worker $(\mathrm{p}=0.035)$, exposure to HMW allergens $(p=0.008)$, and the mutation of workplace $\left(p \leq 10^{-3}\right)$. In addition, WEA was associated with a history of personal and family atopy with respectively $\left(\mathrm{p} \leq 10^{-3}\right)$ and $(\mathrm{p}=$ $0.017)$, work in the transport sector $\left(\mathrm{p} \leq 10^{-3}\right)$ and temporary unfitness to work $\left(\mathrm{p} \leq 10^{-3}\right)$.

Conclusion Allergic asthma in workplace, reflects inappropriate working conditions. The adoption of preventive measures at the same time as medical treatment is the only guarantee to keep the ability to work.

\section{P-443 MANAGEMENT OF BLOOD EXPOSURE ACCIDENTS VICTIMS EXPOSED TO HIV BY THE OCCUPATIONAL HEALTH DEPARTMENT OF RABTA HOSPITAL}

Emna Baraketi, Jihen Hsinet, Saloua Ismail, Nihel Khouja, 'Siwar Chemingui, Amani Dallagi, Ines Aissa, Aida Benzarti, Abdelmajid Ben Jemaa. 'Hôpital La Rabta, Tunisia

\subsection{6/OEM-2021-EPI.331}

Introduction Post-exposure prophylaxis (PEP) reduces the risk of transmission of human immunodeficiency virus (HIV) following blood exposure accidents (BEA). However, there are no updated Tunisian recommendations for its use.

Objectives To describe the circumstances of BEA requiring PEP and to evaluate the prescribing practices of PEP and clinical, biological and serological follow-up of victims.

Methods We conducted a descriptive retrospective study of victims of BEA who sought medical care in the occupational medicine department of Rabta hospital in Tunis, from 1998 to 2018 and for whom a PEP was prescribed.

Results A total of 456 cases were included with a median age of $30 \pm 10.3$ years and a sex-ratio of 0.56 . They were healthcare workers in $98 \%$ of cases, mainly physicians (35.4\%), hospital porters and cleaning staff (22.3\%). The most frequent tasks leading to the accidents were waste disposal $(16 \%)$ and taking blood samples $(10.8 \%)$. In cases of known sources $(72.6 \%)$, the PEP was prescribed because the sources were HIV positive $(23.6 \%)$ or had risk factors for 
HIV infection, mainly scarifications and/or tattoos (23.1\%), drug abuse (12.9\%) or history of hepatitis B and/or C $(12 \%)$. In cases of unknown sources, PEP was prescribed if the BEA occurred in a suspicious socio-epidemiological context. The PEP was started within four hours of the BEA in $42.8 \%$ of cases and covered 28 days in $56.8 \%$ of cases. Poor compliance with PEP was noted in $55 \%$ of cases. The serological follow-up at one, three and six months was carried out in $11.6 \%, 6.5 \%$ and $4.5 \%$ of cases, respectively. Positive HIV serology of the source was significantly associated with compliance to serological follow-up at one month $(p=0.023)$ and at three months $(p=0.029)$. None of the cases had a seroconversion.

Conclusion A well-managed PEP prevents the risk of HIV seroconversion following a BEA. It is crucial to develop a national updated guideline for management of BEA and PEP.

\section{P-444 SMALL BUSINESS EXPERIENCES WITH COVID-19 PROTECTION MEASURES: A CROSS-SECTIONAL STUDY COMPARING EMPLOYER AND EMPLOYEE PERSPECTIVES IN RURAL NEW BRUNSWICK.}

${ }^{1}$ Kim Cullen, Emily Kingston. ${ }^{1}$ Memorial University, Canada

10.1136/OEM-2021-EPI.332

Introduction There is a limited understanding of what is known about the implications of recent occupational health and safety (OHS) protection measures on small business management and employees during the coronavirus disease (COVID-19) pandemic. The study examines the different COVID-19 measures that have been used by small businesses in Miramichi, New Brunswick.

Objectives The study identifies the most common OHS protection measures in use within small businesses during COVID19 and explores whether differences exist in perspectives of employees and managers of small businesses on the most effective OHS protection measures used.

Methods Recruitment was collected through convenience sampling between February 6th, 2021 and March 9th, 2021. Participants for the online survey included business management personnel and employees from Miramichi, NB. The cross-sectional study used a web-based survey containing 25 items concerning demographics $(\mathrm{n}=7)$, experiences working during COVID-19 ( $n=7)$, and information and experiences with characteristics of personal protective equipment (PPE) used $(\mathrm{n}=11)$.

Results Results showed moderate ratings of positive endorsement (60\%) from both employers and employees on the use of COVID-19 OHS protection measures. No significant differences were found between employer and employee perceptions on the effectiveness of employed protection measures. The most frequently used protection measures utilized in these small businesses constitute the three lowest levels of control represented on the NIOSH Hierarchy of Controls: engineering controls, administrative controls, and PPE.

Conclusion This study provides new knowledge through the collection of stakeholder perspectives about how current workplace strategies to prevent the spread of COVID-19 in small businesses and may help guide future recommendations for small businesses dealing with other OHS and public health crises. BRAZIL IN 2019

${ }^{1}$ Renata Barbosa Vilaça Marques de Carvalho, Luciane Gabriele Pereira Gomes Lopes, Simone Bezerra da Silva, Ivonice Meire do Carmo Gentil, Daiane Oliveira dos Santos, Lorena Gomes Santos, Rafaela Cordeiro Freire. 'UFBA, Brazil

\subsection{6/OEM-2021-EPI.333}

Introduction Civil construction is responsible for most occupational accidents, generating social and economic losses and causing serious damage to workers' health.

Objective To characterize the cases of serious work accidents (SWA) reported in civil construction in Brazil.

Methodology: This is a descriptive study with a quantitative approach with secondary data in the public domain extracted from SWA records from Notifiable Diseases Information System occurred in 2019. Population data were obtained from the Continuous National Household Sample Survey, from the Brazilian Institute of Geography and Statistics. The incidence coefficient was calculated and presented by 100 thousand workers.

Results 10,551 cases of SWA were reported in civil construction in 2019, most of them concentrated in the Southeast (33.14\%) and South (22.72\%) regions of the country. The occupations with the highest number of registered cases were bricklayers $(70.10 \%)$, installation electricians $(12.10 \%)$ and carpenters (10.56\%). Most of the injured workers were male (99.02\%), black (57.35\%), aged between 30-59 years (73.19\%) and with incomplete elementary education (31.75\%). Accidents were mainly caused by contact with other and unspecified machinery (8.81\%), fall on and from scaffolding $(6.81 \%)$ and fall from, out of or through building or structure $(5,94 \%)$. The most affected part of the body was the hands $(27.28 \%)$ and most cases evolved with some type of disability (61.73\%). Fatal accidents stand for $3.07 \%$. The incidence coefficient was 154.64 cases/100 thousand workers.

Conclusion SWA were concentrated in the most productive regions of the country and occur mainly in adult workers, blacks and with low education. In addition, it assumes that the causes of accidents were mainly related to the work environment and the use of individual and collective protective equipment. Thus, measures for the prevention and promotion of workers' health are recommended to minimize the occurrence of work accidents.

\section{P-451 BIOLOGICAL AGE AS AN INDICATOR OF THE HEALTH STATE OF MINERS}

${ }^{1}$ Nurbek Yerdessov, Asset Izdenov. 'Karaganda Medical University, Kazakhstan

\subsection{6/OEM-2021-EPI.334}

Introduction The study of the biological age of miners living and working in the central Kazakhstan allows us to talk about such a phenomenon as premature aging. The main group of men with a moderate acceleration in the rate of aging was made up of workers in occupations with the most harmful working conditions, i.e., tunnellers and drillers with more than 10-15 years of work experience.

Objectives The purpose of our research was to study the health status of workers in the mining industry of central Kazakhstan, based on the results of determining the biological age. 